\title{
DESIGN DE LEQUES: UMA \\ COLEÇÃO DE LEQUES ARTESANAIS AMBIVALENTES DE GÊNERO.
}

\section{FAN DESIGN: A COLLECTION OF AGENDER CRAFT FANS}

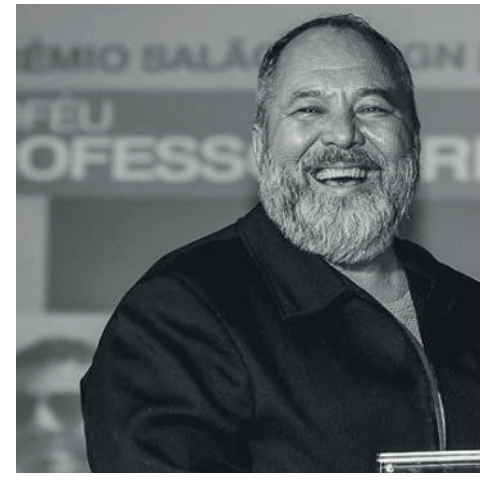

\section{Cláudio Roberto Y Goya}

Doutor, FAU USP - Faculdade de Arquitetura e Urbanismo da Universidade de São Paulo.

Departamento de Design, UNESP - Universidade Estadual Paulista - Júlio de Mesquita Filho

goyaclaudio@hotmail.com

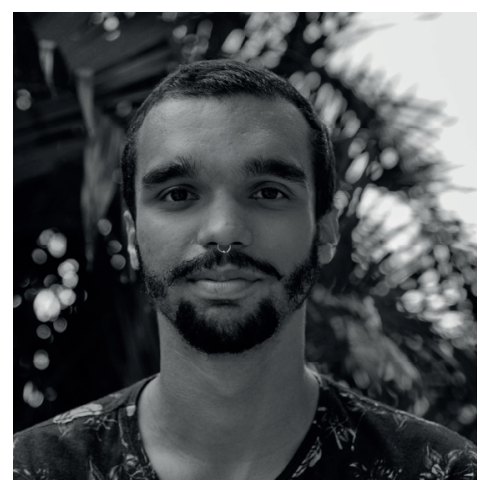

\section{Michael Garcia da Rocha}

Graduando, UNESP - Universidade Estadual Paulista -

Júlio de Mesquita Filho

Departamento de Design, UNESP - Universidade Estadual Paulista "Júlio de Mesquita Filho".

garciar.michael@gmail.com 


\section{RESUMO}

Neste artigo será relatada a produção da Coleção de Leques Artesanais Ambivalentes de Gênero, sua metodologia, seus materiais e seus resultados finais. Para tal, pesquisou-se a história do leque oriental e ocidental a fim de analisar seu papel nas sociedades da época e suas mudanças estéticas ao decorrer do tempo. Também fora pesquisado discussões sobre a formação do gênero nas sociedades contemporâneas, suas influências e como ela serve de expoente para desigualdades sociais. Paralelo a isso, é apresentada uma breve história da moda ambivalente e como ela está ligada diretamente ao feminismo e a luta pela igualdade de gênero.

\section{PALAVRAS-CHAVE}

Leque, Moda Ambivalente, Artesanato.

\section{ABSTRACT}

This article will present the production of the Collection of Agender Craft Fans, its methodology, materials and final results. For this, the history of the Eastern and Western fan was researched to analyze its importance at the societies and how its aesthetic changes through the time. Discussions had also been researched on formation of gender in contemporary societies, their influences and how it serves as an exponent for gender inequality. At the same time, a brief history of ambivalent fashion and how it is directly linked to feminism and the struggle for gender equality are exposed.

\section{KEYWORDS}

Hand Fan, Agender, Arts and Crafts

\section{INTRODUÇÃO}

O leque é um objeto de origem oriental, com data de criação imprecisa, que pode ser atribuída ao imperador chinês Hsien Yuan em 2697 a.C., ao imperador Shun em 2255 a.C. ou ao primeiro governante da dinastia Chou em 1122 a.C. (RHEAD, G. W, 1910), mas que tem uma história de grande importância para todas as sociedades as quais fez parte. Em sua concepção, esses objetos não eram definidos como acessórios de moda exclusivamente femininos, contudo, por questões históricas abordadas neste estudo, sua introdução nas sociedades ocidentais se deu dessa forma. Em meados do séc. XX, o leque deixou de ser presente no cotidiano das sociedades ocidentais, que o tinham absorvido tão 
bem quanto costume. Isso o impossibilitou de ser influenciado por ideologias, discussões e acontecimentos históricos que fomentam o pensamento e a sociedade contemporânea.

Uma dessas influências impossibilitadas está atrelada às discussões sobre o binarismo de gênero e como ele influencia histórica e socialmente os produtos de design, moda, publicidade, dentre outros.

Precisamos rejeitar o caráter fixo e permanente da oposição binária, precisamos de uma historicização e de uma desconstrução autêntica dos termos da diferença sexual. Temos que ficar mais atentas às distinções entre nosso vocabulário de análise e o material que queremos analisar. (SCOTT, J. W. 1989, p. 18) Tais perspectivas, aliadas a demandas de atendimento da Comunidade Cornéia Vlieg, que tem o artesanato como maior fonte de trabalho, por meio do trabalho proposto pelo Labsol - Laboratório de Design Solidário, são as bases para a elaboração deste estudo que visa a criação de cinco leques artesanais ambivalentes de gênero, para a comunidade Cornélia Vlieg, com a perspectiva de geração de renda para seus colaboradores. Como o objetivo secundário, pretende-se propor o uso do leque como acessório de moda contemporâneo e ambivalente de gênero.

\subsection{HISTÓRIA DOS LEQUES}

Mesmo com as imprecisões históricas quanto à data em que o leque foi criado, é possível ter certeza da geolocalização de sua gênese: a China. Neste contexto é possível constatar a importância do leque como acessório de moda, visto que ele simbolizava poder, classe e elegância. Sua estética era diferenciada da concepção ocidental contemporânea de leque, pois estes eram fixos, como abanadores, e confeccionados a partir de penas de diversos tipos de aves como gansos, pavões, faisões e falcões, sendo esses últimos as opções mais nobres. Outra diferença ante a concepção contemporânea é que os leques eram acessórios binários nessa época, usado tanto por homens quanto por mulheres. O Japão é o berço do Leque Dobrável de Hastes e Folhas cuja imagem está presente usualmente em nossas mentes quando pensamos leque. A evidência mais tardia de seu uso é uma pintura de parede datada em VI d.C. em Fukuoka, no entanto as primeiras referências literárias do leque dobrável são datadas no séc. X (Fan Circle International, 2017). Era formado por hastes unidas por uma ligadura de metal, formando uma abertura radial que era preenchida por delicados papeis orientais. Sua introdução na cultura chinesa se deu durante a Dinastia Sung (960 - 1279 d.C.). No início seu uso era extremamente elitista, 
sendo usado somente pela alta classe da dinastia em questão, porém com a mudança para a Dinastia Yuan (1271 - 1368 d.C.), o leque dobrável começou a ser usado popularmente, fato este dado principalmente pela circulação de muitos estrangeiros que usavam leques de papel coloridos e alegres.

Com o passar do tempo as características do leque mudaram, principalmente devido às mudanças políticas que aconteciam nestes dois países. No Japão, por exemplo, a produção desses objetos ficou praticamente parada durante o Período Edo (1690-1868), em que devido ao fechamento dos portos e outras medidas políticas, passou a ser produzido em pequena escala e de forma descartável, para uso doméstico. Esse período durou 265 anos e com seu fim o Japão abriu seus portos para comércio e também para as influências externas que alavancaram a produção artesanal nacional. $O$ isolamento do mundo tornou os países da Europa e os EUA ávidos por produtos japoneses, capítulo esse que ficou conhecido como "Moda Japonesa".

$\mathrm{Na}$ China, também por exemplo, perdeu-se muito na arte da produção artesanal dos leques, principalmente em relação a sua expressão cultural. As produções feitas nos séculos XVIII e XIX foram quase que exclusivamente para atender o gosto ocidental, usando materiais como casco de tartaruga e madrepérola, que antes não eram usados pelos chineses. Abdicou-se muitas vezes de produzir seus clássicos Foldingfans (Leques dobráveis de hastes e folhas) para produzir os Briséfans (Leques dobráveis de hastes) que eram leques de hastes conectados por uma ligadura, mas que não tinham uma folha que as unia radialmente. Com a revolução cultural na China do séc. $X X$, quase toda sua tradição na produção de leques artesanais fora perdida, por mais que alguns artistas dessa época tentassem resgatá-la e trazê-la de volta às artes, o esforço não passou de uma tentativa falha em função da distância geográfica na grande China.

No início do século XVI os leques fixos já tinham se estabelecido como acessório de moda na sociedade europeia. Muitos retratos da realeza já o adotavam como elemento. Estes objetos geralmente eram produzidos com penas luxuosas e usados como ornamento ou como joia. A precursora desse acessório na realeza europeia foi a Rainha Elizabeth I, da Inglaterra, que fascinada por moda, ditava o que era usado por todos na época.

Vale ressaltar que a produção dos leques, quando não importada do Oriente, era concebida tanto por homens quanto por mulheres, porém seu uso era de exclusividade feminina. Nenhum autor pesquisado consegue definir de fato a razão de esse acessório ter se tornado um ícone feminino, no entanto todos citam a rainha Elizabeth I como um símbolo de extrema importância para o 
estabelecimento do leque como acessório indispensável na comunidade europeia. Essas evidências podem levar à hipótese de que a influência da Rainha na moda, de certa forma, impossibilitou que o leque se tornasse um ícone masculino também, visto que Elizabeth I mudou totalmente a estética europeia. Seus ícones eram fortes e ela necessitava deles para impor-se com respeito na sociedade patriarcal da Inglaterra na época.

Com o decorrer do século XVI o leque dobrável de folhas chega a Europa e em pouco tempo ele já tinha se disseminado entre os integrantes da corte, mais uma vez por influência da Rainha Elizabeth I. Este tipo de leque será utilizado massificadamente pelos europeus até a década de 1930 e então desaparecerá, como veremos adiante.

Com o fim do reinado da Rainha Elizabeth I em 1603, os leques perdem seu cargo de acessório exclusivo da corte e se estabelecem como acessório de moda na alta elite aristocrática da Europa. Com o consequente aumento na procura pelo objeto, a produção local foi ampliada para complementar aqueles que até então vinham em maioria do oriente.

Devido a esse aumento, os maiores produtores do leque estavam dispostos na Inglaterra, França e Itália. Com o passar do tempo, sua estética foi fortemente influenciada pelos períodos artísticos pelos quais perpassou e com essa formação morfológica visual, aos poucos cada país foi adicionando características únicas em suas produções. A Inglaterra, por exemplo, por volta de 1740 aderiu ao uso de folhas de ouro em suas produções como característica local.

Com a virada do século, algumas características estéticas do leque tiveram alterações principalmente por influência da moda. É possível constatar o fato no trecho retirado do portal do Círculo Internacional do Leque:

No começo do séc., XIX, os leques, após seu apogeu entre os séculos XVII e XVIII, tiveram seu período de declínio. A Moda simplista e rústica foi o que ditava o momento. Com isso, os leques se tornaram muito delicados e muitas vezes não eram mais do que o tamanho da palma de uma pessoa, pois os vestidos eram mais finos e tinham bolsos menores. (http:// www.fancircleinternational.org/history/fans-in-19th-century-europe/, acessado em 05/2017).

No decorrer do séc. XIX tecnologias de produção apareceram, como a máquina de bordar (apresentada no Palácio de Cristal em 1851) que influenciou fortemente o papel do leque como produto artesanal. Tais técnicas transformaram 
esse acessório de moda em um produto decadente e com meios de produção massificados. "[...]tudo isso serviu para que os leques fossem mais acessíveis para o grande público, contudo ele foi reduzido de um objeto de arte para um produto de massificada produção." (Fan Circle International, 2017).

A Primeira Guerra Mundial, no começo do século XX, fez com que a produção e comercialização do leque, assim como de diversos itens, praticamente desaparecesse. Sendo assim, nenhum desenvolvimento do papel social ou da estética do leque ocorrera.

No período da Primeira Guerra Mundial, as mulheres tiveram que defender-se e defender sua família, em razão da ausência da figura masculina. Precisaram trabalhar e adquirir papéis sociais que antes só eram desempenhados por homens (considerando a sociedade patriarcal) e essa troca as empoderou de tal forma que mesmo depois do fim da guerra elas não queriam abdicar da sua independência nem do seu próprio dinheiro. O fato influenciara a moda diretamente: as silhuetas dos vestidos passaram a ser tubulares e mais confortáveis, tomando como base o vestuário masculino que sempre foi mais confortável que o feminino.

Ao chegar do século XX, com a Primeira Guerra Mundial, a mulher teve de assumir o controle da maioria das funções sociais, muitas das quais cabiam apenas aos homens. À medida que as mulheres substituíam os homens em suas tarefas, os traços masculinos acabaram por aparecer no vestuário delas. (SCHNEIDER, J, 2014, p. 08).

A década de 1920 foi a última na qual o leque aparece como acessório de moda. Após as mudanças relatadas neste artigo, outras "modas" apareceram como o cigarro e a bebida. Com a impossibilidade de segurar uma bebida, um cigarro e um leque ao mesmo tempo, esse último foi deixado de lado. Concomitantemente, o ventilador elétrico fora inventado, não havendo a necessidade de autorrefrescamento em ambientes fechados. Já em 1930, o leque realmente desaparecera como acessório popular, transformando-se em algo arcaico.

Sendo assim, as mudanças drásticas da sociedade no pós-guerra, aliadas aos avanços tecnológicos ocorridos nesse mesmo momento, fez com que o leque perdesse seus status de acessório de moda indispensável, que foi construído em mais de 4000 anos de história. No entanto, leques publicitários ainda existiam, porém nunca tiveram o mesmo refinamento que os antigos leques artesanais do séc. XVIII. Em alguns países europeus onde o clima é um pouco mais 
temperado, como na Espanha, esses objetos ainda desempenham certo papel como acessório de moda, no entanto, nada comparado com o papel que ele já desempenhara.

\section{GÊNERO E MODA AMBIVALENTE: UM PANORAMA HISTÓRICO}

Antes de adentrar nas análises sobre gênero é importante deixar claro uma diferença teórica entre "sexo" e "gênero": sexo, de acordo com Scott (1995, p.13) são as diferenças físicas e naturais entre homens e mulheres, enquanto gênero é a organização das diferenças sexuais, é o saber que estabelece significados para essas diferenças corporais. Ou seja, nessa definição o sexo são as diferenças anatômicas entre os corpos femininos e masculinos, a genitália, estatura, proporções, enquanto o gênero é o saber que estabelece significados a essas diferenças, que estabelece uma hierarquia entre as diferenças sexuais, que molda o pensamento e a noção de corpo ante a sociedade. Ee essa noção sobre o corpo que estabelece a classificação entre "coisas de homem" e "coisas de mulher". Essa noção sobre sexo e gênero, é adotada por grande parte das pensadoras e pensadores que discutem o papel das ideologias de gênero na sociedade e o feminismo.

Tomando como princípio essa principal diferença, discute-se inicialmente o papel da biologia na formação do gênero, já que ela é a grande área do conhecimento que determinou o que é sexo e que determinou as diferenças fisiológicas entre os seres humanos. Linda Nicholson (2000), em seu estudo "Interpretando o Gênero", discorre inicialmente sobre a relação entre a biologia e a formação do caráter de gênero, no qual ela relata de diversos pontos de vista, como a biologia é determinante para a formação social do gênero e como ela justificou as diferenças que "sempre" existiram entre homens e mulheres.

Tal compreensão do relacionamento entre biologia, comportamento e personalidade, portanto, possibilitou as feministas sustentar a noção, frequentemente associada ao determinismo biológico, de que as constantes da natureza sendo responsáveis por certas constantes sociais, e isso sem ter que aceitar uma desvantagem que se torna crucial na perspectiva feminista, a de que tais constantes sociais não podem ser transformadas. (NICHOLSON, L. 2000, p. 04).

Tendo em vista essa premissa, analisa-se historicamente a percepção de sexo pela ciência e filosofia a fim de perceber a noção da formação do eu, e por 
consequência, a formação do gênero. Essa análise histórica começa com a criação do conceito de raça nos sécs. XVII e XVIII, que potencializaram a noção de diferenciação do ser humano, e que por consequência potencializaram as diferenças entre gêneros.

Nesses séculos a noção de ser humano tornou-se cada vez mais binária e justificada por diversos aspectos médicos/biológicos, como a diferenciação de esqueleto, sistema nervoso entre outros. A causa dessa percepção se dá ao fato de que outas ideologias, como a religião, não eram mais dominantemente influenciadoras na percepção de gênero. Em outras palavras:

[...] Quando a Bíblia ou Aristóteles era a fonte da autoridade sobre como o relacionamento entre mulheres e homens deveria ser compreendido, qualquer diferença alegada entre mulheres e homens era justificada primordialmente através da referência a esses textos. $O$ corpo não era muito importante como fonte. Quando, porém, os textos de Aristóteles e da Bíblia perderam sua autoridade, a natureza se tornou o meio de fundamentação de toda distinção percebida entre mulheres e homens. Na medida em que o corpo passou a ser percebido como representante da natureza, ele assumiu o papel de 'voz' da natureza, ou seja, na medida em que havia uma necessidade percebida de que a distinção masculino/feminino fosse constituída em termos altamente binários, o corpo tinha que "falar" essa distinção de forma binária. A consequência disso foi uma noção "bissexuada" de corpo. (NICHOLSON, L. 2000, p. 13).

O resultado dessa mudança foi, de acordo com Linda Nicholson (2000), a nossa ideia de "Identidade sexual" - um eu masculino ou feminino precisamente diferenciado e profundamente enraizado num corpo contrastado.

As ideologias de gênero baseadas no determinismo biológico perduraram sem grandes mudanças até a Primeira Guerra Mundial, em que mudanças nas sociedades patriarcais quanto o papel social desenvolvido pelas mulheres forneceu forte influência para questionamentos sobre a hierarquia entre homens e mulheres.

Como já introduzido neste estudo, as mulheres do período da Primeira Guerra Mundial tiveram que desempenhar outros papeis sociais dos quais elas eram designadas. Agora, trabalhar, defender a família e ser a figura principal das decisões tomadas era um papel atribuído às mulheres. Com o fim da guerra, muitas dessas mulheres não quiseram abdicar da liberdade, independência e dinheiro, 
conquistados nesse período sem a presença masculina.

Tal rebeldia ante o sistema patriarcal pode ser vista na moda, em que mudanças drásticas, principalmente em relação à silhueta feminina, aconteceram primordialmente pela contribuição da estilista Coco Chanel, que criou peças cujas inspirações vinham do guarda-roupa masculino. Como as roupas femininas até então eram nada confortáveis, muito se aboliu, principalmente a silhueta totalmente demarcada. Na década de 1920, os vestidos eram de modelagem cilíndrica, execrando o uso de espartilhos. (SCHNEIDER, J, 2014).

Passadas quase duas décadas, outra guerra se desencadeia e mais uma vez viu-se mulheres aderindo a papeis ditos masculinos. Com seu fim, outras transformações drásticas podem ser vistas na sociedade ocidental. Os ideais feministas da década de 1960 levaram ao que ficou conhecido como moda unissex, em que peças antes nunca usadas por mulheres, enfim tiveram seu lugar no guarda-roupa.

De maneira geral, percebe-se que a luta pela liberdade feminina e a igualdade social entre mulheres e homens fez com que o universo delas aderisse cada vez mais ao vestuário masculino, impondo seu estilo de vestir e procurando eliminar as diferenças existentes entre roupas até então. Tais mudanças foram motivadas principalmente pelo conforto que as roupas trazem, privilégio que até o momento era usufruído apenas pelos homens.

Contudo, as principais mudanças ocorridas devido aos ideais de igualdade de gênero vieram nas décadas de 1970/80, em que feministas radicais defenderam um conceito de gênero que nega qualquer determinismo biológico e apontaram os moldes da sociedade patriarcal como os definidores de gênero e por consequência do sexismo e outros problemas de igualdade entre pessoas. Levando isso em consideração, algumas pensadoras da época, como Janice Raymond, contestam diversos aspectos da medicina moderna, inclusive em relação à transexualidade, assunto esse que ainda é discutido entre grupos feministas.

Sabemos que somos mulheres que nascemos com cromossomos e anatomia femininos, e que, tenhamos ou não sido socializadas para sermos consideradas "mulheres normais", o patriarcado nos tratou e nos trata como mulheres. (RAYMOND, 1979., p. 114.)

Dessa vertente de feminismo e das discussões de gênero, surge a problemática do que chamamos atualmente como representatividade. Nicholson (2000) relata que esse feminismo que "somente" diferencia mulheres de homens, além 
de gerar uma espécie de natureza da mulher (mesmo que social) acaba por representar um ponto de vista daquelas que produziam esse conteúdo, ou seja, mulheres heterossexuais, brancas e de classe média.

Diante de todas essas discussões sobre as diferenças entre os papeis sociais dos gêneros, como isso é determinado ora pela biologia, ora pela sociedade, observa-se as mudanças que estas ideologias e discussões causaram na moda, como o uso de calça jeans no dia a dia, o uso de polos e de blazers. Isso evidencia o quanto as discussões sociais influenciam a moda direta e indiretamente e como a moda pode servir como instrumento de militância para uma causa ou ideologia. Considerando que a moda está imbuída de discursos de gênero culturalmente construídos e que ela "organiza visualmente a sociedade", definindo e subordinando subjetividades. Percebe-se que a moda ambivalente utiliza dessa ferramenta justamente para quebrar esses estereótipos. Para Schneider $(2014$, p. 11) o conceito de moda ambivalente "se dá no intuito de individualizar cada ser de forma diferente a partir de uma mesma peça de vestuário que agregue gênero e consequentemente novo sentido na construção de individualidades."

\section{METODOLOGIA}

Após as análises históricas relatas neste estudo até então, deu-se início as etapas de criação e produção da coleção de leques ambivalentes de gênero. Para tal, utilizou-se a metodologia de Projeto de Produto (BAXTER, 2011) como base teórica norteadora das etapas projetuais para que a coleção atendesse as motivações e necessidades já citadas neste.

Antes das etapas criativas fora elaborado uma análise de similares que tinha duas metas principais: 1) estabelecer repertório morfológico visual sobre a produção dos leques contemporâneos, e 2) elencar materiais utilizados, que geraram a tabela de análise de similares (TABELA1). Nessa análise foram elencados três referenciais encontrados mediante pesquisa: A loja Kyosendo, a loja Duvelleroy e o Artista Sylvain Le Guen.

Kyosendo é uma loja japonesa que possui duas lojas físicas, uma em Tóquio e outra em Kyoto, além de uma loja virtual. Suas produções são tradicionais, seus leques de hastes e seus leques de hastes e folhas têm formato circular, com temática floral para leques femininos e temática geométrica para leques masculinos. Destaca-se o uso recorrente de madeira e bambu.

Duvelleroy, uma loja francesa, tem uma estética menos formal, principalmente quanto às estampas, que no geral não adotam temáticas florais, mas sim de cultura pop. As hastes são feitas de madeira, que podem ser pintadas ou em na- 
tura, gerando uma composição harmoniosa com as estampas. Existem também leques mais requintados enquanto forma e estética, com recortes precisos em suas folhas ou com formatos diferenciados em suas hastes.

Sylvain Le Guen é o mais desprendido de tradicionalidade. Conforme seu site, Sylvain dá caminhos contemporâneos para materiais cuja vida artística é secular, como marfim ou madrepérola e seu desafio hoje é redescobrir e reinventá-los (Sylvain Le Guen, 2016). Essa característica é notadamente encontrada em suas obras de caráter delicado e preciso, com formas extremamente inovadoras e composições ricas, tanto conceitualmente, quanto esteticamente. Além dos materiais já citados neste parágrafo, Sylvain também utiliza madeira e alumínio para suas hastes. Suas folhas são compostas por materiais diversos como organza, papel, couros diversos, vinil e penas.

Realizadas as análises por similaridade, elaborou-se a seguinte tabela com os dados de materiais levantados em pesquisa. Estes dados nortearam as escolhas dos materiais usados.

TABELA DE ANÁLISE DE MATERIAIS

\begin{tabular}{l|l|l} 
& $\begin{array}{l}\text { MATERIAIS USADOS } \\
\text { EM HASTES. }\end{array}$ & $\begin{array}{l}\text { MATERIAIS USADOS } \\
\text { EM FOLHAS. }\end{array}$ \\
\hline KYOSENDO & Madeira e bambu & Papel \\
\hline DUVELLEROY & $\begin{array}{l}\text { Madeira em natura } \\
\text { ou pintada }\end{array}$ & Tecido e papel \\
\hline SILVAIN Le GUEN & $\begin{array}{l}\text { Marfim, madrepérola, } \\
\text { casco de tartaruga, } \\
\text { madeira e aluminio }\end{array}$ & $\begin{array}{l}\text { Organza, papel, couros } \\
\text { vinile penas. }\end{array}$ \\
\hline
\end{tabular}

Tabela 1 - Análise de materiais. Fonte: produção dos autores.

Após a elaboração desta tabela, decidiu-se os materiais que seriam usados: madeira e organza. Escolheu-se a madeira, pois os beneficiados pela Associação Cornélia Vlieg já estão habituados com o seu manuseio, que proporcionará o requinte e a resistência desejados. A escolha da organza tem a finalidade de explorar sua transparência fisicamente, com o uso de camadas de tecido e con- 
ceitualmente, misturando materiais sóbrios e materiais delicados, mesclando assim características distintas na oposição "masculino vs. feminino"

Com estas resoluções, deu-se início aos rascunhos, que teve o intuito de gerar ideias que são o início projetual. Para Mike Baxter (2011, p. 102), essa etapa é a mais importante para o projeto de produtos pois "a finalidade de geração de ideias é produzir todas as possíveis soluções. A seleção tentará escolher a melhor delas.." Considerando a mesclagem proposta pelos materiais, nesta etapa do desenvolvimento, optou-se pela exploração de formatos mais geométricos e incomuns para reforçar na estética dessa coleção um design ambivalente que negue quaisquer estereótipos formais que estes objetos já tenham repercutido.

Nos rascunhos, muitas ideias foram produzidas, algumas mais abstratas, outras mais concretas. Contudo, antes de escolher as ideias que enfim seriam levadas à frente no projeto, foram cortadas algumas que eram impossíveis de se prototipar, seja por impossibilidade formal ou técnica. Ao final, escolheu-se os cinco leques que farão parte da coleção de leques artesanais ambivalente de gênero (imagem 1). São eles, da direita para esquerda: Leque Monte, Leque Geométrico, Leque Hexagonal, Leque Asa e Leque Bumerangue.

Definidos os cinco modelos que seriam produzidos, foi elaborado o desenho técnico de cada um a fim de obter maior precisão projetual. No desenho das hastes foi utilizado um furo padrão de $3,5 \mathrm{~mm}$, que possibilitou o uso de um mesmo tipo de ligadura para todos. Já em relação a sua altura, muito se variou, principalmente devido a assimetria de três deles (Geométrico, Asa e Monte), pois necessitava-se de uma variância para chegar no formato desejado.

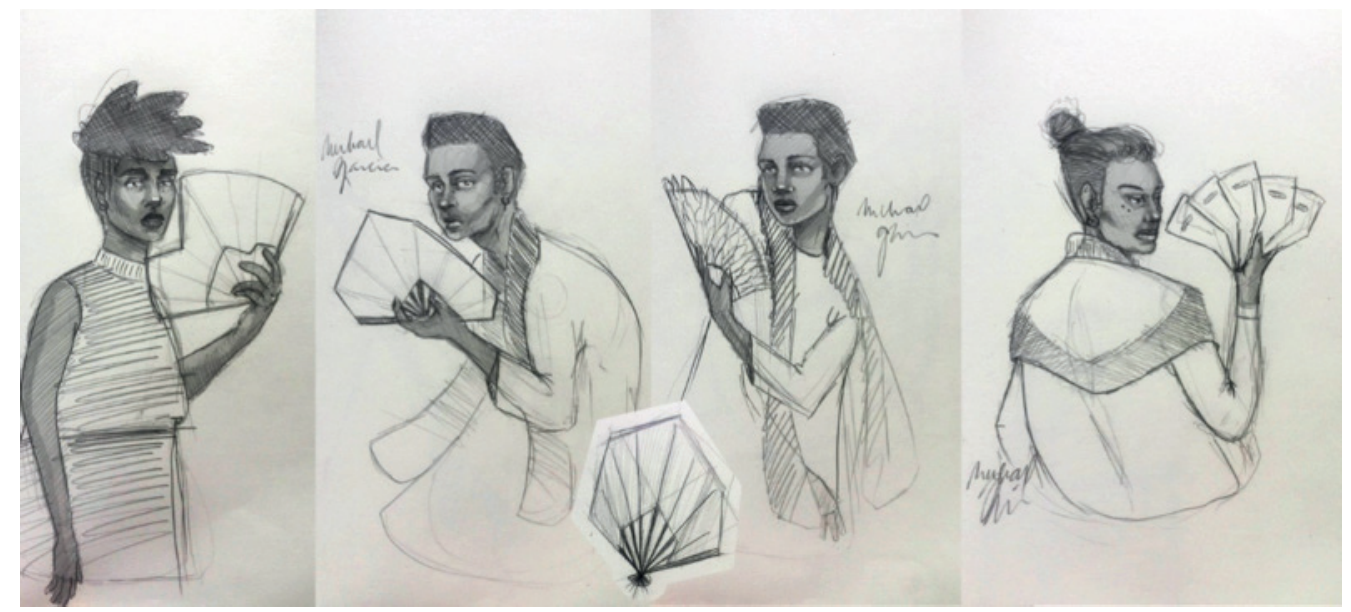

Imagem 1 - Rascunhos Leque Monte, Geométrico, Hexagonal, Asa e Bumerangue. Fonte: produção dos autores. 
Na produção dos desenhos que serviriam de moldes para as folhas dos leques, houve a preocupação de obter duas dobras entre as hastes, uma dobra vale (linha laranja) e uma dobra montanha (linha azul), pois somente assim as hastes conseguem ser coladas nas folhas sem impossibilitar sua abertura e fechamento tão cruciais para o projeto.

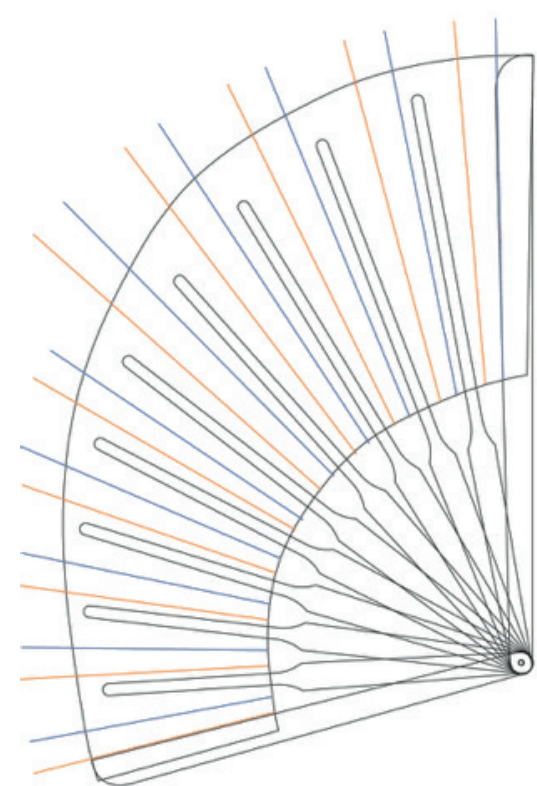

Imagem 2 - Leque Asa. Fonte: produção dos autores.
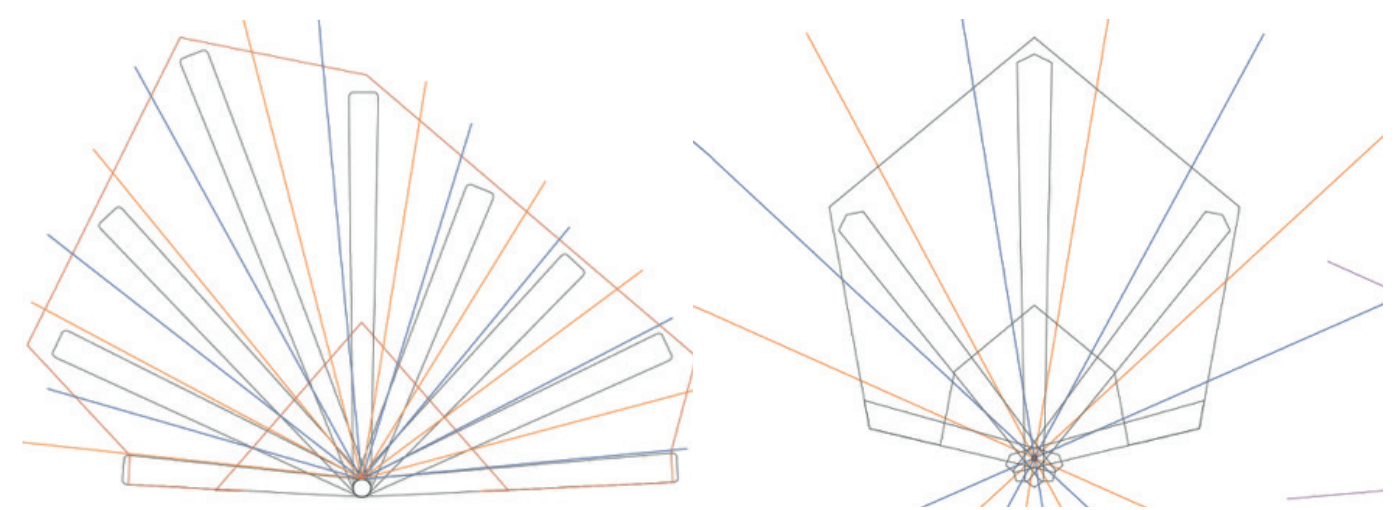

Imagens 3 e 4 - Leques geométrico e hexagonal. Fonte: Produção dos autores. 

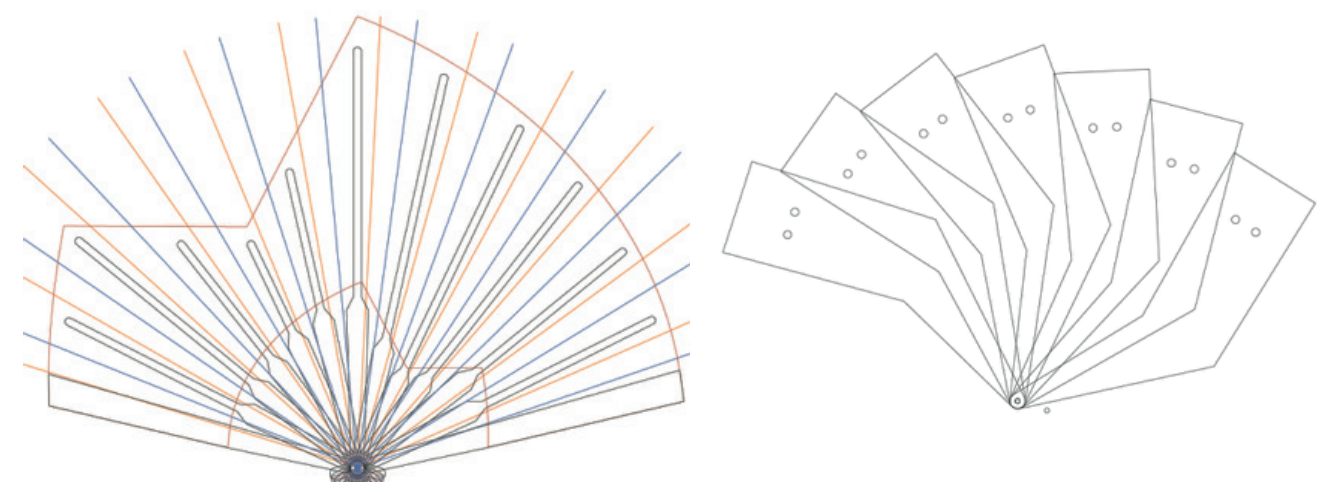

Imagens 5 e 6 - Leques Monte e Bumerangue. Fonte: Produção dos autores.

Outra preocupação projetual foi relacionada ao desenho do recorte interno nos leques Geométrico, Hexagonal e Monte, pois seu formato não radial poderia impossibilitar a abertura e o fechamento necessário caso não houvesse uma folga suficiente entre as hastes. Já no leque Bumerangue (o único leque só de hastes) as preocupações foram menores em função de sua menor complexidade, nota-se apenas furos pelos quais passarão elásticos, que conectarão suas hastes possibilitando sua abertura radial.

Com o término dos desenhos e modelagens, iniciou-se a fase de prototipagem dos leques. Para as hastes, foi aconselhado pelo orientador o corte a laser, devido à grande singularidade destas. Esta medida, além de facilitar a prototipagem, possibilitou que as peças cortadas a laser fossem moldes melhores para a comunidade Cornélia do que um desenho técnico. Sendo assim, entrou-se em contato com uma empresa local especializada em corte a laser e fora solicitado o corte de todas as hastes em MDF $3 \mathrm{~mm}$. Não houve problemas técnicos nesta etapa da produção.

Foram estabelecidos dois tipos de acabamento para as hastes: em natura, para o leque Bumerangue e com pintura, para os leques restantes. Para o acabamento com pintura ocorreu o seguinte processo: lixamento com lixa 200 para retirar algumas imperfeições de corte e deixá-las mais lisas, impermeabilização com uma demão de goma laca, pintura com duas demãos de tinta PVA fosca (preta ou capuccino), lixamento com lixa 400 (se necessário) e envernizamento com verniz spray natural brilhante. Já para o acabamento em natura, decorreram as etapas: lixamento com lixa 200 para retirar imperfeições, impermeabilização com goma laca em 3 demãos, lixamento com lixa 400 (quando necessário) e envernizamento com verniz spray natural brilhante.

Para as folhas, decidiu-se engomá-las com cola branca, na medida de 1 de cola para 5 de água. Com isso, as folhas conseguiram ser vincadas, possibilitando um 
leque mais requintado. Após a goma as folhas foram cortadas como explícito no desenho técnico e vincadas com o auxílio de prendedores e ferro de passar. Com as hastes e as folhas preparadas, iniciou-se a etapa de montagem dos leques. Primeiramente todas as hastes foram unidas por parafusos $1 / 8$ polegadas, com arruelas e porcas de mesma medida. Em seguida, as folhas foram coladas nas hastes que começa pela extremidade da folha que está dobrada. Esta extremidade em questão é colada na parte traseira da primeira guarda, contudo, nas outras hastes, a folha é colada na parte frontal. Para menor marcação de cola no tecido esta foi passada na haste, depois o tecido era disposto no local o qual era pressionado contra uma superfície lisa e reta até sua secagem parcial, que foi acelerada com o uso de soprador térmico na temperatura de $50^{\circ} \mathrm{C}$. Após secagem total, o leque foi fechado e quando necessário, utilizou-se o pincel molhado para retirar alguma marca de cola.

No leque Bumerangue, o único sem folhas, foi introduzido o elástico por todas as hastes com espaçamento suficiente para abertura. Na última haste, o elástico foi colado e suas pontas introduzidas novamente no furo para melhor acabamento. Neste leque também foi utilizada a cola branca, que gerou bons resultados quanto à resistência.

Com intuito de ilustrar de forma dinâmica, foi elaborado um fluxograma que resume todas as etapas metodológicas adotadas neste estudo, desde a análise de similares até as etapas de prototipagem.

\section{FLUXOGRAMA ETAPAS DE PRODUÇÃO}

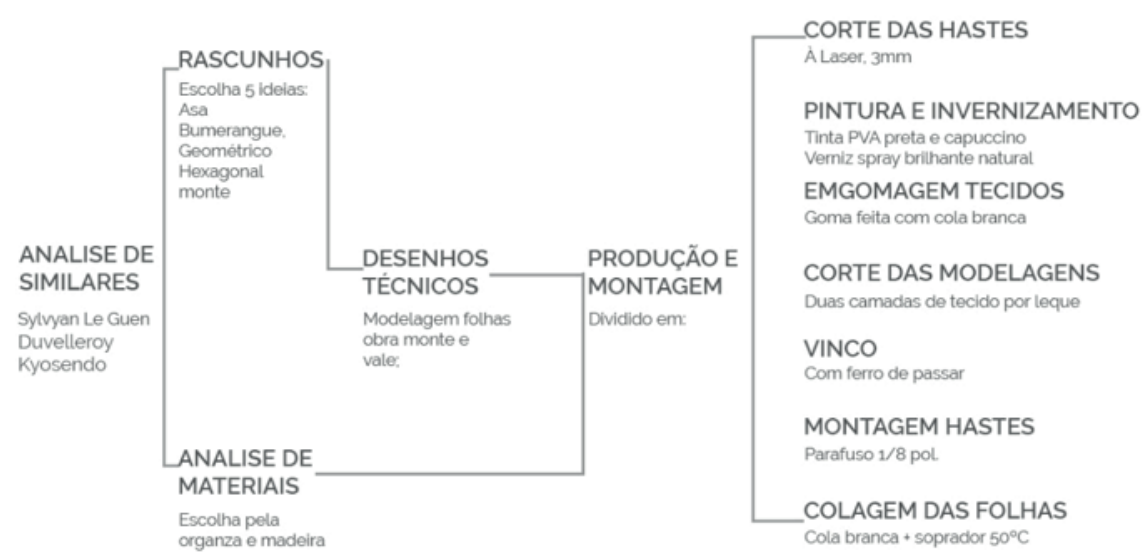

Fluxograma 1 - Etapas de produção. Fonte: produção dos autores 
Ao final das etapas e produção, obteve-se os seguintes resultados: 1) No leque Asa, a estética teve o resultado esperado, pois os materiais conversaram bem entre si, gerando requinte e singularidade. Sua abertura e fechamento estão satisfatórios. 2) O leque bumerangue também obteve abertura e fechamento adequados, o elástico juiz usado para ligar as hastes radialmente dá uma flexibilidade muito interessante, contudo, devido a espessura do MDF utilizado este acessório está pesado demais para uso contínuo. 3) O Leque geométrico também apresenta boa abertura, assim como sua composição estética, contudo a primeira guarda produz uma aba na folha que gera um ruído visual e para sanar a pequena falha técnica serão necessárias adaptações no desenho da dobra. 4) O leque Hexagonal tem abertura bastante adequada, suas hastes alongadas permitem flexibilidade o que causa bom abano, contudo, suas guardas, por serem pequenas, causam problemas de pegada em mãos grandes. 5) O leque Monte teve melhor acabamento: suas hastes mais finas e sua composição de cores possibilitou uma delicadeza estilística muito condizente com características típicas dos leques. Sua abertura e fechamento estão satisfatórias, contudo, devido seu número de hastes (num total de treze) este leque ficou espesso demais, o que prejudica um pouco a pegada do mesmo. Uma possível resolução disso é a utilização de hastes mais finas no miolo do leque, contudo isso pode afetar sua resistência, devido ao fato de sua guarda não ser a maior haste do leque.

Os resultados podem ser avaliados a seguir, com imagens que ilustram com clareza os resultados estéticos obtidos.

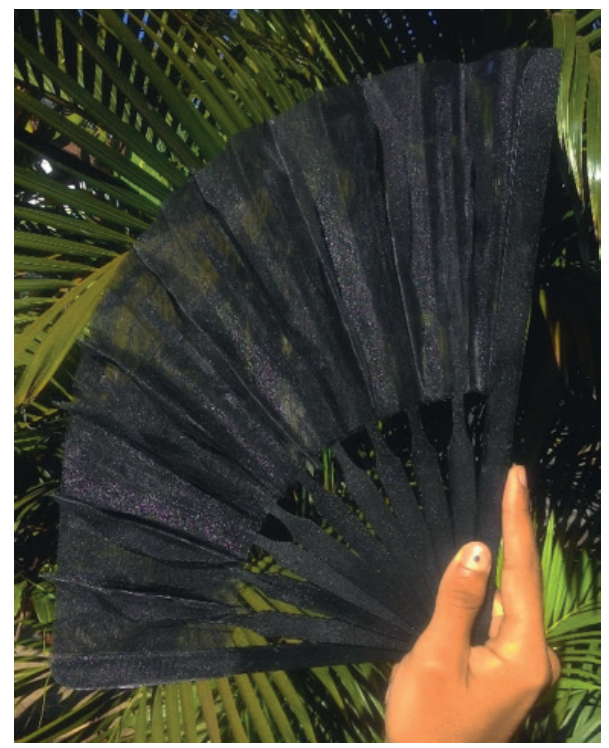

Imagem 7- Resultado Leque Asa. Fonte: produção dos autores 


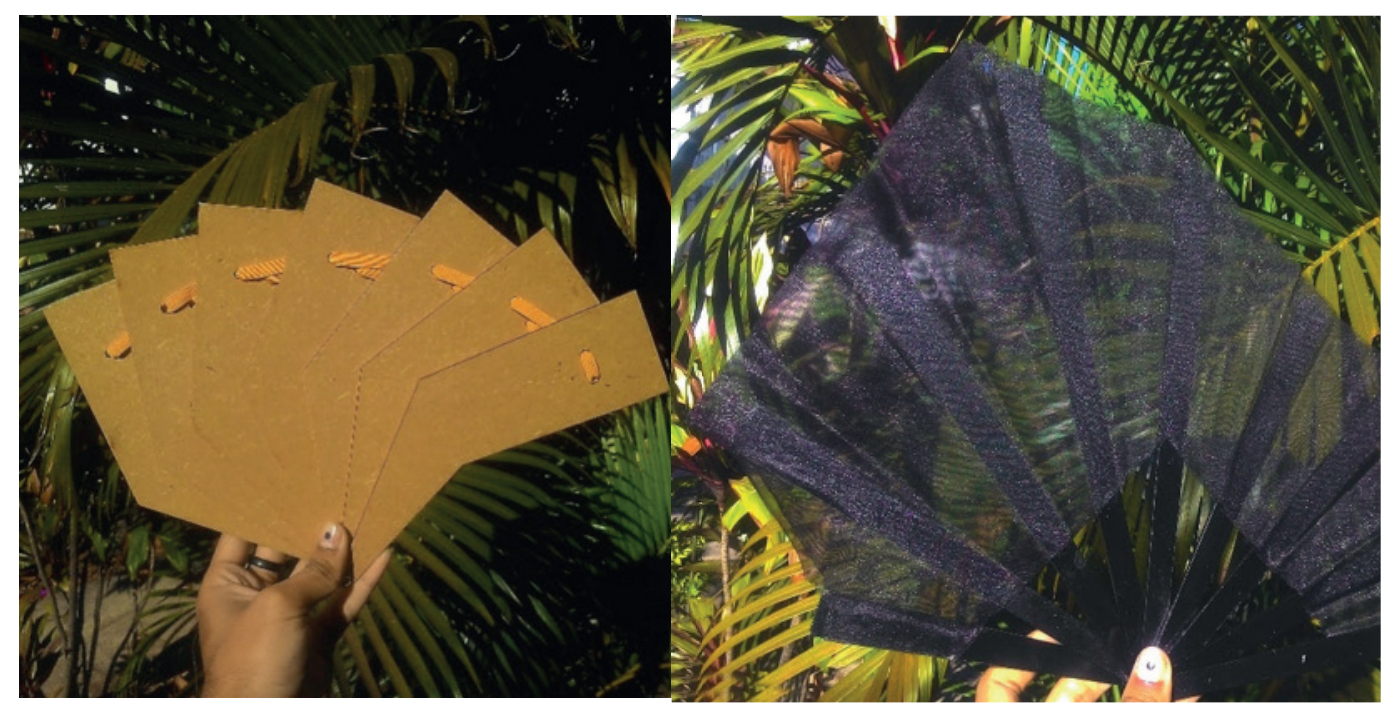

Imagens 8 e 9 - Resultdo Leques Bumerangue e Geométrico. Fonte: Produção dos autores.

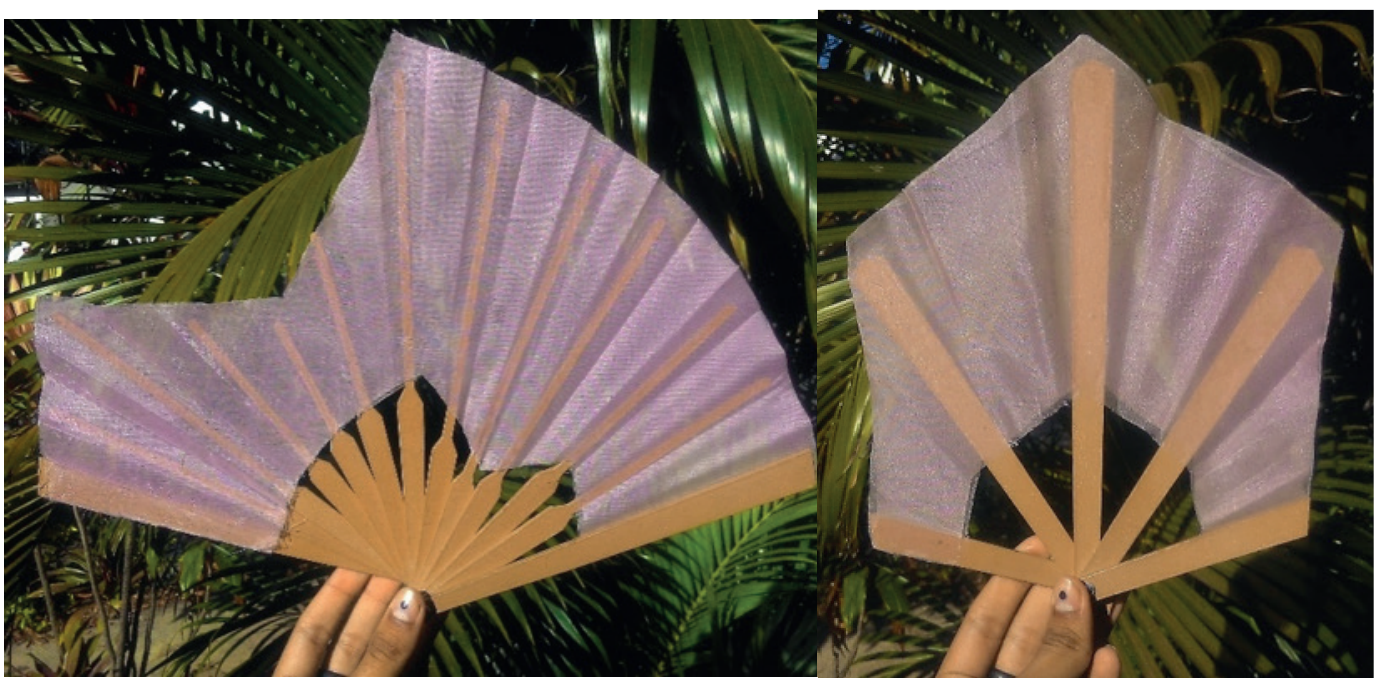

Imagens 10 e 11 - Leques Monte e Hexagonal. Fonte: Produção dos autores.

\section{CONSIDERAÇÕES FINAIS}

Por questões históricas inferidas neste artigo, o leque se estabeleceu como um acessório de moda exclusivamente feminino, ao contrário do que sempre aconteceu no Oriente. Com o passar do tempo ele acabou desaparecendo da cena fashion ocidental, principalmente por outros modismos sociais que influenciaram a vida cotidiana, e por consequência, impossibilitou certas experimentações funcionais e estéticas que a contemporaneidade permite. Poucos artistas e lojas trabalham com o leque, o que o transforma numa grande possibilidade de exploração enquanto projeto de design e enquanto pro- 
duto de ideologias de moda, como a moda ambivalente.

O alinhamento dessas duas vertentes ideológicas pode transformar o leque numa grande ferramenta de militância ante os sistemas sociais os quais a moda ambivalente lutou contra. Todas essas questões ainda estão atreladas a produção artesanal e cultural da Associação Cornélia Vlieg, que além de poder permear tais ideologias conseguiria adicionar novos objetos em sua gama de produções.

Estes pensamentos influenciaram diretamente a Coleção de Leques Artesanais Ambivalentes de Gênero, o que pode ser analisado principalmente pela exploração formal dos leques, os quais fogem do padrão radial presente comumente na cabeça de todos. Tal exploração visa permitir que, por meio da quebra do senso comum do se espera de um leque, ele seja melhor aceito por todos igualitariamente, e assim permeie, mesmo que indiretamente, os ideais da moda ambivalente e da igualdade de gênero.

Sendo assim, a estética dessa coleção é o fator que desencadeia todas as relações entre o consumidor-produto-ideologia. É ela que permite quebrar estereótipos sociais sobre gênero e por consequência, projetar uma sociedade mais igualitária. A Associação Cornélia Vlieg será, caso o projeto seja bem recebido por seus beneficiados, o expoente de disseminação desses objetos e desses ideais. É por meio da cultura artesanal que todas essas ideologias, discutidas há quase cem anos, poderão ser acessadas e é por meio dela que se pretende introduzir a moda ambivalente.

\section{REFERÊNCIAS}

BAXTER, Mike. Projeto de Produto, Guia prático para o design de novos produtos. São Paulo: Editora Blucher, 2011.

DUVELLEROY éventails de mode, 2017, disponível em: <https://eventail-duvelleroy.fr/13-eventails-de-mode> Acesso em Abril de 2017.

INTERNATIONAL fan circle, history of fans, 2017, disponível em: < http://www. fancircleinternational.org/history/>. Acesso em maio de 2017.

KYOSENDO shop online, 2017, disponível em: <https://www.kyosendo.co.jp/ en/shop-en/>. Acesso em abril de 2017.

LEGUEN, Silvayn Biography, 2017, disponível em: <http://www.sylvainleguen. com/indexi.php?page=lignes $>$ Acesso em maio de 2017.

NICHOLSON, L. Interpretando o gênero. Estudos Feministas, 2000.

RHEAD, G. Woolliscroft. History of the Fan, London: Kegan Paul, Trench, Trubner\& Co. Ltd. 1910 
SCHNEIDER, Jessica; Para Além do Gênero: moda ambivalente no século XXI. $4^{\circ}$ encontro Nacional de Pesquisa em Moda, Florianópolis.2014.

SCOTT, Joan; Gender: a useful category of historical analyses. Gender and the politics of history. New York: Columbia University Press. 1989.

Claudio Roberto y Goya possui graduação em Arquitetura e Urbanismo pela Universidade de São Paulo (1986) e doutorado em Arquitetura e Urbanismo pela Universidade de São Paulo (1999). Professor assistente da Universidade Estadual Paulista Júlio de Mesquita Filho no curso de Design. Coordenador do Curso de Design da FAAC Unesp Bauru. Atualmente é Professor Assistente Doutor no Departamento de Design da Universidade Estadual Paulista Júlio - UNESP. Participa do Laboratório de Pesquisa, Extensão e Ensino Design Contemporâneo e do Grupo de Pesquisa Design Contemporâneo: sistemas, objetos e cultura.

Entre 2010 e 2013 assumiu a coordenação da Incubadora Tecnológica de Cooperativas Populares da Unesp Campus de Bauru. Desde março de 2007 coordena o Laboratório de Design Solidário da FAAC UNESP Bauru - Labsol, onde pesquisa tecnologias sociais relacionadas ao Design e atende comunidades em atividades de extensão. O Labsol tem como referenciais teóricos a Economia Solidária, a Sustentabilidade, o Ecodesign e a Dialogicidade.

Michael Garcia da Rocha é graduando Design Gráfico pela UNESP - Universidade Estadual Paulista "Júlio de Mesquita Filho" Campus Bauru. Tem experiência no desenvolvimento de projetos gráficos e de produtos. Desde 2015 participa do Laboratório de Design Solidário, Labsol, desenvolvendo projetos e pesquisas nos campos do Design Solidário, Ecodesign, Design Sustentável, Design de Fantasias e Design de Moda. Dentre os trabalhos elaborados no campo da moda, destaca-se o artigo premiado "A Joalheria Contemporânea e a Sustentabilidade na Produção de Ornamentos de Papel" Apresentado no $3 \circ$ Simpósio Interdesigners, no ano de 2016. 